\title{
UN 및 주요 양자원조기관의 과학기술혁신 프로그램 사례 분석
}

목 차

I. 서 론

II. UN 및 주요 양자원조기관의 과학기술혁신 프로그램

1. 국제연합(UN)

2. 미국 국제개발처(USAID)

3. 일본 국제협력기구(JICA)

4. 독일 국제개발협력청(GIZ)

5. 스웨덴 국제개발협력청(SIDA)

6. 한국 국제개발협력단(KOICA)

7. 기관 간 프로그램 비교분석

III. 결론

참고문헌 


\section{요 약}

$\mathrm{SDGs}$ 는 과학기술혁신의 중요성을 강조하고 있다. SDGs의 거의 모든 목표들은 과 학기술혁신과 밀접하게 관련되어 있다고 볼 수 있다. 그러나 과학기술혁신의 개념은 매우 포괄적이며 광범위한 해석의 여지가 있다. 본 연구에서는 UN과 주요 양자원조기 관의 과학기술혁신 프로그램의 현황을 조사하고 특성을 비교분석하였다. UN은 최빈국 을 위한 기술은행 및 기술촉진메커니즘 개발 등, 주로 개발도상국이 특허, 논문 등의 기술정보에 용이하게 접근하도록 지원하는 프로그램을 추진하고 있다. 주요 양자원조기 관의 프로그램 분석 결과, USAID은 다양한 프로그램을 운영하고 있었다. JICA와 $\mathrm{SIDA}$ 는 주로 연구활동을 지원하는 것으로 나타났다. KOICA와 GIZ는 혁신시스템 관점에서 종합적 접근을 한다는 유사성을 지니고 있었다. 과학기술혁신의 중요성은 명 확하나, 기존 추진사업과 구별되는 명확한 성과를 얻기 위해서는 기관별 전략수립을 통해 체계적인 사업수행을 추진할 필요가 있다.

주제어: 과학기술혁신, $\mathrm{UN}$, 기술은행, 기술촉진메커니즘, 양자원조기관

\section{I. 서론}

2015년 9월 채택된 지속가능개발목표(Sustainable Development Goals, 이하 SDGs)는 총 17 개의 목표, 169 개의 세부 목표로 구성되었다. 지난 15 년간의 개발의제였던 새천년개발목 표(Millenium Development Goals, 이하 MDGs)가 8개의 목표로 비교적 간단했던 것과 비교할 때, SDGs는 다루는 대상이 훨씬 다양해졌다고 평가할 수 있다. 또한, 기후변화와 인도적 위기 상황 등 새롭게 대두되고 있는 전 지구적 이슈들까지 포함시키고 있다. 이러한 변화는 개발 협력을 둘러싼 다양한 환경의 변화와 관련이 있다(한국국제협력단, 2015).

$\mathrm{SDGs}$ 를 지난 MDGs와 구분 짓는 여러 요소들 중 하나는 과학기술혁신(Science, Technology and Innovation, STI)의 중요성에 대한 강조이다. SDGs는 17번 목표인 '이행수 단과 글로벌 파트너십(Global Partnership)'의 하위분야로 '기술(technology)'을 포함하고 있다. 여기에는 남-남, 남-북 및 삼각협력을 통해 과학기술혁신에 대한 접근성을 강화할 것, 환경 친화적 기술들을 개발도상국에 유리한 조건으로 이전하고 확산시킬 것, 최빈국(LeastDeveloped Countries, LDC)을 위한 기술은행(Technology Bank) 및 기술촉진메커니즘 
(Technology Facilitation Mechanism, TFM) 가동 등의 세부 목표가 포함되어 있다(UN, 2015a).

그런데 SDGs에서 과학기술혁신의 강조는 17 번 목표에만 국한되는 것은 아니다. 이우성 외 10 인(2015)은 SDGs의 17 개 목표 중 10 번(불평등 경감), 13 번(기후변화 대응), 16 번(포용적 사회제도) 등 3 개의 목표를 제외한 나머지 14 개 목표가 과학기술혁신과 관련성을 내포하고 있다고 분석하였다. 또, 세부 목표 기준으로는 총 24 개의 세부 목표가 과학기술혁신과 관련되어 있다고 분석하였다. 그런데 과학기술혁신과 관련성이 낮다고 분석된 3개의 목표 중 기후변화 대응과 관련된 13 번 목표의 경우, '기술'이나 '과학'이라는 표현을 포함하고 있지 않지만, 목표 달성을 위해서는 기술 활용이 필수적이다. 따라서 SDGs의 거의 모든 목표들이 과학기술혁신과 밀접하게 연관되어 있다고 할 수 있다.

기존의 여러 연구는 국가 간 경제 격차를 좁혀나가기 위해서는 후발국의 기술혁신역량이 중요하다는 결과를 보여주고 있다(이근, 2014). 그럼에도 불구하고 지금까지 개발도상국의 과 학기술혁신 역량 강화를 위한 구체적 방안에 대해 국제사회 차원에서 광범위한 논의가 이루어진 사례는 다소 찾아보기 어렵다. 지나간 MDGs만 보더라도 그렇다. 따라서 SDGs와 같이 파급력 이 높은 어젠다에서 과학기술혁신이 전면적으로 부각된 것은 개발 협력 분야의 중요한 패러다임 전환이라고 볼 수 있다.

한편, 한국은 2015년 12월 박근혜 전 대통령의 국제연합 교육과학문화기구(United Nations Educational, Scientific and Cultural Organization, 이하 UNESCO) 특별연설을 계기로 '보다 나은 삶을 위한 과학기술혁신(STI for Better Life)' 이니셔티브를 발표하였다. 동 이니 셔티브는 개발도상국의 과학기술혁신 역량 강화를 목적으로 2016년부터 2020년까지 5년간 2 억 달러의 지원을 이행하겠다는 내용을 담고 있다. 동 이니셔티브 발표의 후속조치로 2016년 2월 국무조정실은 목표 체계와 주요 프로그램 유형 등을 정의한 마스터플랜을 발표하였다(국무 조정실, 2016).

하지만 과학기술혁신의 개념은 매우 포괄적이고 광범위한 해석의 여지를 갖는다. 공적개발원 조(Official Development Assistance, 이하 ODA) 분야에서 과학기술혁신 ODA(또는 과학 기술 $\mathrm{ODA}$ ) 사업을 분류하기 위해 국제적으로 통용되는 기준은 아직까지 존재하지 않는다. 따라서 지원현황을 분석하고 지원계획 수립을 뒷받침하기 위한 자료가 매우 부족한 상황이며, 향후 과학기술혁신 사업을 분류하기 위한 분류체계의 수립이 요구된다(이우성, 2014). 이러한 상황인식을 바탕으로 본 연구에서는 국제연합(United Nations, 이하 UN) 및 주요 양자원조기 관의 과학기술혁신을 주제로 다루는 프로그램의 사례를 비교분석할 것이다. 그리고 분석결과를 
토대로 향후 과학기술혁신 프로그램의 유형 정립 및 전략수립에 필요한 시사점을 도출하고자 한다.

\section{UN 및 주요 양자원조기관의 과학기술혁신 프로그램}

본 장에서는 UN과 주요 양자 원조기관의 과학기술혁신 관련 프로그램 내용을 비교할 것이다. $\mathrm{UN}$ 의 경우, $\mathrm{UN}$ 본부 차원의 프로그램 이외에도 국제연합개발계획(United Nations Development Programme, UNDP), UNESCO, 국제연합환경계획(United Nations Environment Program, 이하 UNEP), 국제연합공업개발기구(United Nations Industrial Development Organization, $\mathrm{UNIDO)}$ 등 산하기관 차원에서 추진하는 관련 프로그램이 있으 나 연구 기간에 제약이 있어 UN 본부 사례로 범위를 한정하였다. UN 본부의 프로그램 사례는 $\mathrm{UN}$ 사무총장 주도로 SDGs 발표와 함께 추진하고 있는 최빈국을 위한 기술은행 및 과학기술혁 신 역량 강화 메커니즘(Technology Bank and Science, Technology, and Innovation Capacity Building Mechanism)을 분석하였다. 주요 양자원조기관의 경우 미국 국제개발처 (United States Agency for International Development, 이하 USAID), 일본 국제협력기 구(Japan International Cooperation Agency, 이하 JICA), 독일 국제협력공사(Deutsche Gesellschaft für Internationale Zusammenarbeit, 이하 GIZ), 스웨덴 국제개발협력청 (Swedish International Development Cooperation Agency, 이하 SIDA), 한국 국제협력 단(Korea International Cooperation Agency, 이하 KOICA)의 프로그램 사례를 분석하였 다. 각 기관의 자료 입수에 제한이 있어 자료 검색 및 확보가 가능한 기관들의 사례를 중심으로 분석하였다. 이는 동 연구의 한계이며, 앞으로의 연구는 추가적인 자료 확보를 통해 보다 많은 기관의 사례를 분석함으로써 본 연구의 결과를 보다 정교화하는 것이 될 것임을 미리 밝힌다.

\section{1. 국제연합(UN)}

\section{가. UN 차원의 과학기술혁신 프로그램 추진구상}

$\mathrm{UN} \mathrm{SDGs}$ 에는 과학기술혁신에 관련된 구체적인 프로그램이 명시되어 있는데, 바로 목표 17 에 나타난 기술은행 및 기술촉진메커니즘에 대한 내용이 그것이다. 해당 내용을 검토함으로 써 $\mathrm{UN}$ 이 과학기술혁신 이슈에 대해 어떻게 접근하는지 파악할 수 있다. 
SDG 17 은 이행수단과 글로벌 파트너십에 관한 내용을 다루고 있다. 아래 <표 $1>$ 에서 보는 바와 같이, 그 중 17.6 부터 17.8 까지는'기술’이라는 주제로 엮여 있다.

제I장

\section{제II장}

〈표 1〉SDG 17의 하위주제인 '기술'의 세부지표

\section{기술}

17.6 UN 차원에서 현존하고 있는 조정 메커니즘과, 글로벌 기술촉진메커니즘을 통해 과학기술혁신 분야에서의 남-북 · 남-남 · 삼각협력, 지역 및 국제협력 강화와 상호 합의에 의한 지식공유 증진

17.6.1 국가 간 협력 형태별 과학기술협력에 관한 협약 및 프로그램 수

17.6.2 인구 100 명당 속도별 유선 광대역 인터넷 가입자 수

17.7 상호 합의에 의한 양허 및 특혜 조건을 포함하여, 개발도상국에 유리한 조건으로 환경적으로 건전한 기술의 개발, 이전, 보급과 확산

17.7.1 개발도상국에 환경적으로 건전한 기술의 개발, 이전, 보급, 확산을 촉진하기 위해 승인된 재원의 총액

17.8 2017년까지 최빈국을 위한 기술은행 및 과학기술혁신 역량구축 메커니즘의 완전 가동, ICT를 비롯한 실행기술의 활용도 향상

17.8.1 인터넷 사용자 비율

출처: KOICA (2015), SDGs 최종지표에 맞게 일부 번역 내용 저자 수정

이 중 17.6 과 17.8 에 나타난 기술은행과 기술촉진메커니즘은 UN 차원에서 구체적으로 추진 하고 있는 정책이다. SDGs를 발표하기에 앞서, 2015년 7월 에티오피아 아디스아바바에서 열린 제 3 차 개발재원 총회의 결과는 이러한 정책들의 향후 추진 방향과 과학기술혁신의 중요성 에 대한 국제사회 인식의 흐름을 이해하는데 중요한 참고가 된다. 제 3 차 개발재원 총회 결과 채택된 아디스아바바 행동계획에서는 최빈국을 위한 기술은행 및 기술촉진메커니즘의 실현을 위한 합의문이 포함되었다. 기술은행은 특허은행 등 기술정보의 제공체계를 주로 의미한다. 기술촉진메커니즘은 회원국뿐만 아니라 시민사회, 과학계, 민간부문의 다양한 이해관계자들이 참여하는 것을 기본 방향으로 설정하였으며, 구체적 방안으로는 온라인 플랫폼과 포럼 등을 제시하였다. 또 기술촉진메커니즘은 과학기술혁신에 관련된 UN 기구들의 통합된 활동을 추구 하였다.

기술은행과 기술촉진메커니즘은 지금까지 개발도상국들이 원하는 수준의 기술이전이 제대로 이루어지지 않았다는 문제인식을 바탕에 두고 있다고 할 수 있다. 그러나 여전히 선진국과 개발도상국 간 의견의 차이는 존재하고 있어서 최종 합의가 이루어지고 이행되기까지의 절차가 매끄럽게 흘러갈 수 있을지 주목된다. 하지만 선진국과 개발도상국 간 기술이전을 둘러싼 의견 
차이가 존재함에도 불구하고, 기술은행 및 기술촉진메커니즘의 구축에 대한 합의가 이루어졌다 는 것은 최소한 과학기술혁신이 국제사회의 SDGs 달성을 위해 매우 중요한 요인이라는 것에 대해 충분한 공감대가 형성되었음을 유추할 수 있게 해 준다.

\section{나. 기술은행의 개념}

'UN 최빈국을 위한 기술은행(UN Technology Bank for the Least Developed Countries)' 은 2017년까지 구축을 완료하고 정상적으로 작동하는 것을 목표로 한다. 기술은행에 대한 구체 적인 논의는 개발재원에 대한 논의와 병행하여 이루어졌는데, 특히 2011년 5월에 터키 이스탄 불에서 진행되었던 제4차 UN 최빈국회의(UN Least-Developed Countries Summit)를 기 점으로 본격화되었다고 할 수 있다. 동 회의에서는 최빈국의 과학 연구 역량 및 혁신 기반을 강화하기 위한 기술은행 및 과학기술정보 지원체계(Technology Bank and Science, Technology and Information Supporting Mechanism)1) 구축에 관한 논의가 진행되었고, 그 결과는 이스탄불 행동계획(Istanbul Programme of Actions, IPoA)에 반영되었다(UN, 2011).

기술은행 및 과학기술혁신 지원체계(Science, Technology and Innovation Supporting Mechanism, 이하 STIM)는 2013년 7월경 발행된 UN 사무총장 보고서(A/68/217)에서 좀 더 구체화 되었다. 여기에는 $\triangle$ 특허은행(Patents Bank) $\triangle$ 과학기술 연구 성과 DB공유체계 (Science and Technology Research Depository Facility) $\triangle$ 과학기술혁신 지원 메커니즘 (Science, Technology and Innovation Supporting Mechanism) 등이 주요 구성요소로 포함되어 있다. 기술은행에 관한 세부내용의 형성은 UN 최빈국-내륙국고위대표실(UN Office of High Representative for the Least Developed Countries, Landlocked Developing Countries and Small Island Developing States, UN-OHRLLS)에서 주도적으로 담당하 고 있으며, 터키에서 장소 제공 등 기술은행에 대한 주도적인 역할을 담당하기로 결정되었다 (UN, 2013).

반기문 전(前) UN 사무총장은 2014년 11월, 기술은행의 범위와 기능을 선행적으로 연구하기 위한 고위급 패널을 구성하였다. 동 패널은 의장인 르완다 출신의 무렌지(Roman Murenzi) 교수 등 총 11 명으로 구성되었다. 이 패널은 약 1 년에 가까운 작업을 통해 “기술은행에 대한 타당성조사 결과보고서(Feasibility Study for a United Nations Technology Bank for

1) 문서에 따라 표기의 방식에서는 약간의 차이가 발견된다. 이스탄불 행동계획에서는 "기술은행 및 과학기술정보 지원체 계”로 기술되었으나, SDGs에서는 “기술은행 및 과학기술혁신 역량 강화 메커니즘”으로 표현되었다. 주된 표현은

“Technology Bank and Science, Technology, and Innovation-Supporting Mechanism”이다. 
the Least Developed Countries)"를 작성하였다. 동 보고서는 약 100쪽에 달하는 분량이며, 2015년 9월, SDGs 채택보다 약간 이른 시기에 공개되었다.

타당성조사 보고서(2015b)에 따르면, 향후 설립될 기술은행은 크게 두 가지 기능으로 구성된 다. 하나는 STIM이고 다른 하나는 지적재산권 은행(Intellectual Property Bank, 이하 IP Bank)이다. STIM은 최빈국들의 과학기술혁신 수용 역량을 강화하고 지식 네트워크를 형성하 기 위한 목적을 지닌다. 한편 IP Bank는 최빈국들의 특허 및 지적재산권에 대한 접근성을 높이기 위한 목적으로 추진된다. 타당성조사 수행 과정에서 기술은행과 관련성이 높을 것으로 판단된 기존의 국제 프로그램들을 분석한 결과, 대부분 기술이전에 관련된 조항을 포함하고 있기는 하지만, 구체적으로 이를 조율하는 기제가 마련되어 있지 않거나 파편화 되어 있고, 기술이전의 목적과 내용 및 대상국 선정 과정이 구체적으로 진행되지 않는 것으로 파악되었다. 기술은행이 STIM과 IP Bank로 이루어진 구조를 갖게 된 것은 이러한 분석으로부터 비롯되었 다(UN, 2015a). 기술은행은 구체적인 활동들이 이루어질 수 있는 체계를 조성하여 “빠른 성과 (quick impact)'를 거두는데 주안점을 두고 있는 것으로 파악된다.

$\mathrm{STIM}$ 의 구체적인 목표를 한마디로 정리하면, '지식네트워크 구축을 통한 최빈국들의 정보 접근성 향상'이라고 할 수 있다. 타당성조사 보고서는 STIM이 현존하는 UN의 민관협력 프로 그램인 'Research4Life'와 국가별로 존재하는 '국가 연구개발 및 교육 네트워크(National Research and Education Networks, 이하 NREN)'와 협업하고, 이러한 프로그램들을 기반 으로 발전해 나가야 한다고 권고하고 있다.

UN Research4Life는 세계보건기구(World Health Organization, WHO), 세계식량농업 기구(Food and Agriculture Organization, FAO), UNEP, 세계지적재산권기구(World Intellectual Property Organization, 이하 WIPO) 등의 국제기구, 코넬대, 예일대 등 주요대 학, 국제과학기술보건출판협회(International Association of Scientific, Technical \& Medical Publishers) 및 185 개에 달하는 국제적인 과학전문 출판기구들이 포함된 민관협력 파트너십이다. Research4Life는 농업, 보건, 환경 및 혁신을 주제로 하는 지식 콘텐츠를 개발도 상국에 무상 또는 낮은 가격에 제공하는 프로그램이다.

$\mathrm{NREN}$ 은 16 개의 최빈국을 포함하여 전 세계 110 여 개 국가에 구축되어 있는 국가 과학기술 연구 네트워크라고 할 수 있다. 고성능 컴퓨터 및 초고속 통신망을 활용하여 연구기관, 대학, 도서관 등 교육 및 연구기관을 하나로 연결하여 연구에 필요한 자원 및 정보를 공유하는 시스템 이라고 할 수 있다. NREN이 설립되지 않은 국가에서는 지역 단위의 연구교육망(Regional Research and Education Network)을 설립하여 유사한 기능을 수행하기도 한다. STIM은 
이와 같이 연구에 필요한 자료의 접근성을 높이고, 연구정보교환 및 협업을 위한 통신 네트워크 를 구축하여 최빈국의 과학기술혁신 역량을 높일 수 있는 기반 조성을 추구한다고 볼 수 있다.

한편, IP Bank의 구체적인 목표는 한마디로 최빈국들이 지적재산권을 보다 쉽게 이용할 수 있는 체계를 구축하는 것이라고 정리할 수 있다. STIM과 달리 IP Bank는 발전의 토대로 삼을 수 있는 기존 프로그램이 존재하지 않는다. 따라서 IP Bank는 회원국들 간 자발적이고 상호 합의에 기반을 둔 기술이전 과정을 지원하고, 전문적 조언을 제공하는 활동을 지원하게 될 것이다. 그리고 이를 통해 최빈국이 새로운 경제성장의 동력을 만들고, 구조적인 문제를 해결하여 글로벌 지적재산권 체계에 합류하는 것을 추구하려는 목표를 갖고 있다.

\section{다. 기술은행의 초기 활동: STIM}

타당성조사 보고서(2015)는 기술은행이 초기단계(initial phase)에서 추진할 수 있는 활동들 을 제안하고 있다. 우선 STIM의 경우 크게 두 개의 하위 프로그램으로 구분된다. 하나는 ‘디지털 연구 접근 및 네트워킹(Digital Research Access and Networking, 이하 DRAN)'이 고, 다른 하나는 '과학기술혁신 정책 및 역량구축지원(STI Policy and Capacity Building, 이하 $\mathrm{SPCB})$ '이다.

DRAN은 다시 'Digital Access for Research Transfer and Transformation(이하 DARTT)'와 'NREN Facilitation'의 두 가지 활동들로 구분된다. DARTT는 앞서 Research4 Life를 기반으로 활동을 강화해야 한다는 주장을 했던 것과 동일한 맥락이다. 이는 최빈국들을 대상으로 과학 연구 저널, 서적 및 데이터베이스를 무료 또는 매우 저렴한 비용에 사용할 수 있도록 하자는 것이다. Research4Life는 이미 충분한 성공모델을 가지고 있으므로, 이와 같은 서비스에 대한 최빈국들의 수요는 분명하다고 볼 수 있다. 다만, 기존의 Research4Life는 현재 제공하는 서비스의 규모에 맞는 조직으로 구성되어 있으므로 단순히 그 용량을 키우는 작업만으 로 DARTT를 운용할 수는 없음을 지적하고 있다. 또, 회원 국가를 확산시키는 방안으로 지역별 중요한 파트너 국가를 선택하고(방글라데시, 모잠비크, 네팔, 세네갈, 탄자니아, 우간다 등) 이들 국가를 지역의 멘토로 삼아 서비스 권역을 확장시키자는 전략도 가능함을 제시하고 있다.

$\mathrm{NREN}$ 은 앞서 언급되었던 바와 같이 초고속 데이터 통신망을 의미한다. 동 보고서에 따르면, 48 개 최빈국 중 9 개 국가가 전 세계적으로 상호 연결되는 $\mathrm{NREN}$ 을 가지고 있고, 다른 7 개 국가는 NREN을 가지고 있으나 부분적으로 작동하고 제한적인 국가들과만 연결되어 있다. $\mathrm{NREN}$ 은 많은 교육기관과 연구기관들이 타 기관들과 연계됨으로써 다양한 정보를 획득할 수 있고, 교류의 기회를 가질 수 있다는 점에서 매우 효과적이다. 기술은행은 이러한 네트워크를 
통해 보유하고 있는 다양한 지식들을 쉽게 공유하겠다는 의도를 가지고 있다. NREN을 갖고 있는 국가들에게는 제공할 수 있는 다양한 정보와 서비스를 제공하는 한편, 아직 NREN이 구축되지 않은 국가들에게는 세계은행(World Bank), 유럽연합 집행위원회(European Commission) 등과 협업을 통해 동 네트워크의 구축을 지원하려는 계획을 가지고 있는 것으로 보인다.

한편, STIM의 초기 활동 중에는 ‘SPCB’도 포함되어 있다. $\mathrm{SPCB}$ 를 추진하는 이유는 매우 명확하다. 이는 최빈국과 선진국 간의 경제력 격차는 과학기술혁신 역량의 차이에서 비롯된다는 인식에서 시작된다. 그리고 이러한 차이는 선진국들이 최빈국들에게 정책수립과 혁신역량구축 을 지원함으로써 줄여 나갈 수 있다는 생각이 바탕이 되었다. 여기서 말하는 정책 및 혁신역량구 축 지원은 다양한 기관을 통해 각기 다른 모습으로 추진될 수 있다.

동 보고서는 $\mathrm{SPCB}$ 의 세부 활동유형으로 총 여덟 가지 모델을 제시하고 있다. 첫 번째는, 과학기술혁신 정책 및 전략 페이퍼들을 확산시키는 것이다. 이것은 정보공유의 차원으로, $\mathrm{SPCB}$ 를 성공적으로 지원하기 위해서는 최빈국들이 기존의 정책사례들에 대한 일정 수준이상 의 지식 축적이 필요하다는 인식에서 비롯되었다.

두 번째 모델은 선진 (연구)기관들과 최빈국들 간의 협업 네트워크를 구축하는 것이다. 이러 한 네트워크를 통해 각 국가별로 과학기술혁신 분야의 우선순위를 찾아낼 수 있으며, 어떠한 지원이 필요한지 적절히 진단해 낼 수 있다.

세 번째는 국가별 과학한림원(Academy of Science)을 지원하는 것이다. 최빈국 중에는 과학한림원이 설립되지 않은 국가들이 많은데, 이러한 과학한림원 설립을 지원한다. 이렇게 해서 설립된 한림원은 국제한림원연합회(InterAcademy Partnership, IAP), 세계과학아카데 미(The World Academy of Science, TWAS)와 같은 글로벌 네트워크에 참여하여 새로운 정보와 기회를 획득할 수 있다. 또 국내적으로는 이러한 한림원이 국가 개발 정책(National Development Policies)의 수립에서 일정한 역할을 담당할 수 있을 것으로 기대하고 있다.

네 번째는 고등교육기관의 과학기술혁신 역량을 구축하는 것이다. 이미 최빈국의 많은 고등 교육기관들이 여러 공여기관(donor)으로부터 지원을 받고 있다. $\mathrm{SPCB}$ 는 현존하는 공여기관 들의 목록을 정리하고 이것을 최빈국 기관들과 공유함으로써 공여기관과 수원기관 간의 원활한 연계를 지원할 것이다.

다섯 번째는 최빈국 연구자들에게 연구제안서 작성에 대해 교육시키는 것이다. 최빈국 연구 
자들도 선진국 연구자들과 마찬가지로 다양한 연구재원을 활용할 수 있다. 그러기 위해서는 제안서 작성(Grant-writing) 및 지원 절차에 대해 잘 알고 있어야 하므로, 최빈국 연구자들에 게 이러한 역량을 지원하려는 것이다. 이와 같은 교육을 실행하는 방식으로 온라인 모듈을 통한 콘텐츠 제공 방식이 다루어지고 있다.

여섯 번째는 연구 활동에서 협업을 지원하는 것이다. $\mathrm{SPCB}$ 프로그램은 최빈국 연구자들에 게 Research4Life와 같은 네트워크 허브를 기반으로 공동연구자를 찾을 수 있도록 지원하려는 계획을 가지고 있다. 이는 관심분야가 비슷하거나, 동료평가(peer review)를 수행해 줄 수 있는 학자들을 쉽게 찾아내고 연결될 수 있는 기반을 조성하는 노력으로 나타날 것으로 예측된 다. 그러나 공동연구, 연구교류를 위한 재원 조성 등 연구 협업을 발생시키기 위한 가시적인 인센티브는 제시되지 않고 있다.

일곱 번째는 연구 성과의 특허출원을 지원하는 것이다. 동 보고서는 특허출원 지원에 관한 부분을 비중 있게 다루고 있다. 최빈국들은 연구기반과 실력은 다소 뒤쳐질 수 있으나 상당한 전통지식(traditional knowledge)을 보유하고 있고, 또 지리적 특성에 따라 생겨나는 고유한 생산물들이 있는 경우도 있다. 최빈국의 이러한 조건들은 각 국가에 이익을 가져다주어야 하는 데 이를 위해서는 법적으로 권리를 보호받을 수 있어야 한다. 또, 최빈국 연구자들이 특허 자체 에 생소하기 때문에 연구 성과를 내놓고도 그 이익을 충분히 전유하지 못하는 경우도 발생하는 데 이러한 현상을 방지하기 위해서도 특허출원을 지원하는 것은 중요한 행위로 여겨진다. 특허 출원을 지원하기 위한 활동에는 여러 가지가 있을 수 있는데, 하나는 특허출원에 대해 연구자들 을 교육시키는 것이다. 또 다른 하나는 $\mathrm{SPCB}$ 프로그램이 최빈국들에게 협상에 필요한 자문을 제공해 주는 것이다. 앞서 언급한 전통지식 및 특산물로 인해 타 국가와의 공동연구가 추진되는 경우, 최빈국은 상대적으로 지식과 경험이 부족하여 불리한 계약조건을 만들 수 있는데, SPCB 는 여기에 개입하여 최빈국의 이익을 보호하려는 계획을 갖고 있는 것으로 보인다. 또, 최빈국 학자에게 어떠한 저널이 영향력이 있고 중요한 것인지를 구분하여 보여주는 역할을 수행하여 연구 성과를 지킬 수 있도록 지원하려는 의도를 갖고 있다고 생각된다.

마지막 여덟 번째는 디아스포라에 접근하는 것이다. 최빈국 출신의 연구자들이 전 세계에 흩어져 있는 경우가 많은데, $\mathrm{SPCB}$ 프로그램은 이러한 디아스포라를 연결하는 '디아스포라 과학기술혁신 정보 기반'을 구축할 것이다.

정리하면, 기술은행의 두 가지 구성요소 중 STIM은 주로 네트워크 구축을 통해 최빈국 연구자들의 정보 접근성을 확대하고, 협업을 용이하게 하기 위한 활동들로 이루어질 전망이다. 그 외에 특허출원 및 연구제안서 작성 등을 통해 새로운 기회를 탐색하거나, 연구 성과에 대한 
권리를 보호받을 수 있도록 돕기 위한 활동들이 추진될 것으로 판단된다. 한편, 과학기술혁신을 지원하는 활동은 다양한 수혜자들을 대상으로 할 수 있으나, 기술은행에서 설정한 수혜자는 주로 독립적으로 과학기술 분야 연구를 수행할 수 있는 연구자들에게 초점이 맞춰져 있다고 볼 수 있다. 그러한 연구자들을 키워내는 교육과정이나, 연구기관의 물리적 여건을 개선하는 등의 활동은 세부 활동에 반영되어 있지 않다. 이러한 수혜자층의 선택 이유에 대해 동 타당성조 사 보고서에서 명확히 설명하고 있지는 않으나, $\mathrm{UN}$ 차원에서 도달할 수 있는 영역으로 선택과 집중을 한 것으로 보인다.

제I장

\section{제II장}

\section{라. 기술은행의 초기 활동: IP Bank}

동 보고서는 기술은행이 IP Bank와 관련하여 초기에 추진할 다섯 가지 활동을 제시하고 있다. 첫째, 최빈국의 기술 수요 발굴을 지원하는 것이다. 최빈국이 기존에 수행한 기술 수요분 석(need assessments) 결과를 토대로 IP Bank는 각 최빈국의 위한 기술 우선순위를 도출해 야 한다고 강조하고 있다. 또, 자발적 기술이전의 성사를 위한 제안 요청 사항을 정리하는 한편, 최빈국들이 지적재산권을 제공하는 주체들과 적절히 소통할 수 있도록 지원할 것을 강조하고 있다.

둘째, 연구개발(Research and Development, R\&D) 및 성과검증을 위한 정보 접근을 지원 하는 것이다. 동 보고서는 IP Bank가 STIM 및 Research4Life와의 긴밀한 연계를 통해 최빈 국의 학계, 공공기관 등의 연구자, 또는 민간부문의 기술개발 주체들이 기술개발에 관한 정보에 접근할 수 있도록 기술적, 재정적 지원을 해야 한다고 강조한다. 이러한 사례로 $\mathrm{WIPO}$ 의 기술혁 신지원센터(Technology and Innovation Support Centres, 이하 TISC)를 들고 있으나, 특허지형보고서(Patent Landscape Reports, PLRs)와 같은 복잡한 문서에 대한 접근이 충분 히 이루어지지 않는다는 점도 지적하고 있다.

셋째, 전통적인 지적재산권에 관련된 역량 강화를 지원하는 것이다. 동 보고서는 IP Bank가 지적재산권에 관련된 정책형성, 법제도 구축, 행정, 규제, 지적재산권의 활용 등의 분야에서 최빈국의 역량개발을 우선적으로 지원해야 한다고 강조하고 있다. 또, 이러한 분야로 실질적인 지원활동이 집중될 수 있도록 하는 것이 IP Bank의 역할이라고 강조하고 있다. 현재 최빈국을 위한 기술이전 프로그램이 없다는 점을 감안할 때, 기술은행은 지적재산권과 관련하여 역량 강화를 지원하는데 중요한 역할을 담당할 수 있을 것으로 기대된다.

넷째, 최빈국의 지적재산권 취득과 기술이전을 지원하는 것이다. IP Bank가 초기단계에서 지원할 수 있는 영역이 제한적이지만, 그렇다고 해서 최빈국의 기술 획득 수요가 사라지는 
것은 아니다. 보고서는 이러한 점을 고려하여 IP Bank가 최빈국의 지적재산권을 획득할 수 있도록 무료 법률 상담 프로그램, 기술보유국 및 최빈국 양측 모두를 위한 전문적 조언을 수행하 고 가이드라인을 개발하는 것이 필요함을 강조하고 있다.

마지막으로, 민간부문의 참여를 활성화시키는 것이다. 동 보고서는 이러한 활성화를 위한 수단 의 사례로써 국제기구인 '범대서양 비즈니스 협의체(Trans-Atlantic Business Dialogue, 이하 TABD)'를 언급하고 있다. 동 협의체는 미국과 유럽 기업들의 최고경영자(Chief Executive Officer, 이하 CEO), 미국의 장관급 인사, 그리고 유럽연합(European Union, EU) 위원들로 구성되며, 기업 $\mathrm{CEO}$ 들이 주도하는 대화채널을 구축하기 위해 구성되었다. 동 협의체는 매우 오랜 세월 지속되며 기업 간 또는 기업-정부 간 용이한 협업을 이끌어내는 효과를 지닌 것으로 인정받고 있다. 동 보고서는 IP Bank가 성장잠재력이 높은 국가들 간에 TABD와 같은 협의체 를 구성할 수 있도록 주도적인 역할을 해서 최빈국이 투자, 협동, 혁신의 새로운 주역이 될 수 있음을 어필해야 한다고 강조하고 있다.

\section{2. 미국 국제개발처(USAID)}

$\mathrm{USAID}$ 는 가장 큰 규모의 원조를 수행하는 기관인 만큼, 과학기술혁신 분야에서도 매우 다양한 형태의 프로그램을 운영하고 있다. 여기에는 우선 2014년에 시작된 Global Development Lab 프로그램이 있다. 동 프로그램은 국제개발에 관련된 여러 문제들을 민간의 기술역량을 활용하여 해결하기 위한 취지로 시작되었다. 이는 스타트업(start-up)을 지원하기 위한 프로그램과 절차상 매우 유사한 측면이 있다.

연구자들의 개별 연구 과제를 지원하는 프로그램으로는 PEER (Partnership for Enhanced Engagement in Research)라는 이름의 프로그램이 있다. PEER 프로그램은 개발도상국의 과학자들에게 경쟁방식으로 연구비를 지원하는 프로그램이다. 이 프로그램은 미국 국가과학재 단(National Science Foundation)의 유관기관들과 파트너십을 형성하여 공동연구 또는 교육 에서의 협력을 추진하게 된다. PEER 프로그램은 대상 국가의 범위와 연구 과제의 주제가 한정되어 있다.

수원국 연구인력, 연구기관의 역량 강화를 지원하는 프로그램으로는 HEPII(Higher Education Partnership for Innovation and Impact)가 있다. HEPII는 수원국의 고등교육기관을 중심으 로 연구자들을 육성하고, 기관의 역량 강화를 지원한다. 또한 과학, 기술, 공학적 방법을 토대로 한 개발 문제 해결을 지원한다. 
$\mathrm{USAID}$ 는 특정 기술 분야 전문기관과의 협력 하에 특정 지역의 개발도상국들과 포괄적으로 협력하는 방식의 'SERVIR2)' 프로그램을 가지고 있다. SERVIR는 USAID가 미국 항공우주 국(National Aeronautics and Space Administration, NASA)과 함께 설립한 조인트벤처 로 기후변화 및 자연재해에 취약한 특정 지역 국가들에게 위성정보를 제공하는 시스템이다. 이 프로그램에는 SERVIR-Africa, SERVIR-Mekong, SERVIR-Himalaya 등이 있다.

USAID는 특정 지역 국가군과 협력하는 프로그램도 가지고 있다. ASEAN-US Science and Technology Fellowship이나 Middle East Regional Cooperation Program(이하 MERC) 등이 여기에 속한다. ASEAN-US 프로그램은 미국과학진흥회(American Association for the Advancement of Science, AAAS)의 펠로십 프로그램을 벤치마킹하고 있으며, 국가수준 또는 아세안 지역수준에서 이루어지는 정책형성 과정에 효과적으로 영향력을 행사할 수 있는 핵심적인 과학자군을 형성하는 것을 목적으로 추진한다.

ASEAN-US가 지역의 정책전문가를 육성하기 위한 목적인 반면, $\mathrm{MERC}$ 는 중동 지역의 농업, 환경, 수자원, 보건 등의 문제를 해결하기 위한 프로그램으로 아랍 과학자들과의 협업을 추진하는 것이다. 이 프로그램은 젊은 과학자들의 육성을 지원하기도 하고, 실제 해당 문제 해결을 위한 기술개발과 적용을 지원하기도 한다. 한 가지 흥미로운 것은 아랍과 이스라엘 과학자들 간의 평화적인 협력과 문화교류를 추진하는 내용도 포함되어 있다는 점이다. 개발 협력 사업의 목표로 지역에 내재된 갈등해결이 반영되는 경우는 흔하지 않다.

한편, USAID는 특정 국가의 과학기술혁신 역량 강화를 위한 프로그램을 운영하기도 하는데, 주요 프로그램으로 필리핀과 추진하는 STRIDE(Science, Technology, Research and Innovation for Development) 프로그램, 인도와 추진하는 US-INDIA STI and Health Cooperatioin 프로그램이 있다. STRIDE 프로그램은 연구자, 창업자들 간의 네트워크 구축부 터 대학의 고등교육 지원, 연구역량 강화까지 지원의 범위가 매우 넓다. 또, 산학연계 연구 프로젝트나 미국의 여러 가지 사례 참관을 위한 방문을 지원하는 등 다양한 목적의 활동들을 지원하기도 한다.

US-INDIA 프로그램은 STRIDE와 비교할 때 좀 더 명확한 지원대상과 범위를 갖는다. 동 프로그램은 미국-인도 간 기술정상회의, 공동위원회 개최 등 정책 레벨에서의 협력으로부터, 항공 우주, 식수, 모자보건, 보건연구, 환경, 에너지 등 다양한 연구주제별 협력체계를 갖추고 있다. 이 프로그램의 독특한 점은 미국과 인도가 서로 윈-윈(win-win)하는 구조를 가지고

2) 'serve' 의 의미를 지닌 스페인어 단어이다. 
있다는 점이다. 미국은 동 프로그램을 통해 인도의 여러 가지 사회문제에 대한 공동의 대응노력 을 추진하는 한편, 인도의 기술력을 활용할 수 있는 분야에서 민관협력 파트너십을 구축하고 있기도 하다.

$\mathrm{USAID}$ 는 과학기술혁신에 관해 다양한 프로그램을 가지고 있다. 주목할 만한 것은 지원대 상의 범위가 파트너 국가 전체, 특정 지역, 개별 국가 등으로 각기 다르고, 각 지원대상별로 중점 분야와 지원방식이 각기 다르게 형성되고 있다는 점이다. 해당지역 또는 국가에 대한 면밀한 분석을 바탕으로 전략적인 접근을 하고 있는 것으로 보인다. 또, 사업유형(modality) 도 매우 다양하게 나타나고 있는데, 민관협력 파트너십을 활용하기도 하고, 연구재원만을 지원하기도 하며, 공동정책 추진에 관한 행사를 개최하기도 하면서 다양한 요소들을 다루고 있다. 타 원조기관은 USAID에 비해 지원방식이 상대적으로 단조롭다는 점을 감안할 때, 이와 같은 USAID의 다양하고 최적화되어 있는 사업모델은 타 원조기관들이 벤치마킹할 사례가 될 수 있을 것이다.

\section{3. 일본 국제협력기구(JICA)}

$\mathrm{JICA}$ 는 개발도상국과 함께 다수의 공동연구 프로그램을 운영하고 있으며, 또한 개발도상국 에 연구자를 파견하는 프로그램을 지속적으로 추진하고 있다. JICA는 과학기술혁신 정책을 수립하거나 연구기관을 설립하는 프로젝트 사업보다는 명확한 연구 성과를 얻어낼 수 있는 프로그램에 중점을 두고 있는 것으로 판단된다.

JICA는 일본의 과학기술청(Japan Science and Technology Agency, 이하 JST)과 함께 공동연구 프로그램인 SATREPS(Science and Technology Research Partnership for Sustainable Development)을 운영하고 있다. 동 프로그램은 JICA와 일본 외무부가 수원국의 연구기관과 협력을 주도하고, 일본 과학기술청 및 교육문화체육과학기술부(Ministry of Education, Culture, Sports, Science and Technology, 이하 MEXT)가 일본 내 연구기관 을 선정한다. 그리고는 행정적으로 JICA 및 외무부가 JST 및 MEXT와 협업하고, 수원국 연구기관은 일본의 연구기관과 협업을 하는 형태로 운영된다. SATREPS는 2008년부터 운영 되고 있으며, 최근 3년 간(2014-2016) 선정된 과제 수는 총 38개로, 해마다 10-14개의 과제가 선정되었다. 지금까지 진행된 프로젝트는 약 절반가량이 아시아 지역에 집중되어 있다.

SATREPS를 통해 수행되는 연구 과제의 목적은 환경, 자원, 식량 등 전 지구적 문제를 해결하는 데에 있다. 기술혁신을 통한 경제발전을 추구하는 것은 아니다. USAID의 'Global 
Development Lab'이 국제사회가 직면한 문제를 해결하기 위해 민간의 혁신역량을 동원하려 는 노력의 일환이라면, 일본 SATREPS는 동일한 시도를 추구하되 기술개발의 주체가 일정 수준의 역량을 지닌 연구기관이라는 차이가 있다. 또, USAID의 프로그램이 궁극적으로 추구하 는 바가 기술혁신의 확산을 통해 변화를 이끌어 내는 것에 있다면, SATREPS는 기술개발 자체에 좀 더 비중을 두고 추진하고 있는 것으로 보인다.

$\mathrm{JICA}$ 는 아프리카 등 개발도상국의 기초과학 발전을 위해 노력하고 있다는 점에서 타 기관의 지원 프로그램과 구별된다. 이러한 노력에는 특정 대학들과 공동연구 추진체계를 만들고 연구를 수행하는 프로그램3) 이외에 일본 학술진흥원(Japan Society for the Promotion of Science, JSPS)과 함께 연구자를 현장에 파견하는 프로그램이 있다. 파견되는 전문가들은 기초의학, 농업, 에너지, 환경 등의 배경을 지니고 있으며, 정해진 연구 과제가 있어 과업이 명확하다는 특성을 지닌다.

JICA는 연구주제가 분명한 과제를 만들어 내고 실제 연구수행을 위해 연구진을 파견하는 등, 개별 연구 과제를 충실히 수행하기 위한 노력을 투입하고 있다. 이러한 부분은 타 원조기관 들의 접근방식과는 구별되는 측면이라고 할 수 있다. 또한, 과제 선정 및 연구자 파견 등에 있어서 타 정부부처와 행정적 협업체계를 구성하고 있다는 점도 중요한 특징이다.

\section{4. 독일 국제개발협력청(GIZ)}

GIZ는 타 기관과 비교할 때, 과학기술혁신 관련 프로그램을 운영함에 있어서 관련 산업과의 연계, 민간부문 개발에 강조점을 드러내는 것으로 파악된다. GIZ는 혁신시스템(Innovation System)의 관점에서 과학기술혁신에 접근을 하기 때문에 타 기관의 관점과 구분된다고 볼 수 있다. 혁신시스템 관점에서는 연구개발 성과가 산업으로 연결되어 부가가치를 창출하는 과정이 궁극적으로 중요하다고 볼 수 있다. GIZ는 국가혁신시스템의 관점에서 정치적·제도적 이슈, 인센티브 시스템, 제도적 여건, 성과 관리 등에 접근하고 있으며, 이러한 관점에서 필요성 이 인정되는 사업을 기획하고 추진하고 있는 것으로 보인다(GTZ, 2010).

GIZ의 프로그램에는 USAID에서 나타나는 '과학기술혁신 역량 강화'와 같은 키워드를 찾아 보기 어렵다. 대개의 경우 기후변화, 수자원, 농업 등 명확한 산업분야를 지정하고, 해당 분야에 서 기술혁신을 지원하는 방식의 프로그램들이 다수 검색된다. 여러 분야에 개방된 기술혁신

3) 케냐 Jomo Kenyatta University of Agriculture and Technology(JKUAT), Pan African University of Basic Science, Technology and Innovation(PAUSTI) 등과 협력하고 있다. 
지원 프로그램들로 가장 유사한 사업모델에는 2014년부터 2016년까지 아세안 국가들과 추진한 '아세안 국가 기술 및 혁신 촉진 프로그램(Promting Innovation and Technology in ASEAN Countries)', 2004년부터 2010년까지 이집트, 요르단, 시리아 등 국가들과 추진한 '근동 국가 중소기업을 위한 기술 및 혁신 촉진 프로그램(Promotion of Innovation and Technology for Small and Medium Sized Enterprises in Near East)' 사업 등이 있다.

하지만 이전에 언급된 국가나 기관에서 추구하는 관련 사업들이 혁신시스템 관점과 무관하다고 성급하게 판단할 수는 없다. 반대로 GIZ가 연구개발사업을 하지 않는다고 결론을 내릴 수도 없다. GIZ는 국제 개발 협력을 위한 농업기술연구에 40 여 년 이상 지속적인 지원을 해오고 있다.

\section{5. 스웨덴 국제개발협력청(SIDA)}

스웨덴의 SIDA는 개발도상국과 정부 차원의 양자 간 연구협력 프로그램을 운영하고 있다. 주로 아프리카, 중남미 국가들과 협력하고 있는 것으로 보인다. SIDA는 연구협력부서 (Department for Research Cooperation, 이하 SAREC)를 중심으로 이러한 지원을 추진하 고 있는데, 주로 연구에 대한 재정 지원이 이루어지고 있다. 지원하는 분야는 이공계 뿐 아니라 사회과학, 보건 등으로 매우 다양하다.

사업사례로, SIDA/SAREC은 볼리비아 에두아르도 몬들라네 대학교(University Eduardo Mondlane, UEM)의 연구역량 강화 지원사업을 추진하였다, ICT와 도서관 개선 등의 활동이 동 사업을 통해 이루어졌다. 사업기간은 1988 년부터 2005년까지 18 년에 걸쳐서 이루어졌고, 사업비는 3,200만 달러를 상회한다. SIDA/SAREC은 탄자니아와도 연구협력 활동을 추진해 왔다. 우선 2004년부터 2008년까지 5년간은 다르에스살람 대학교(University of Dar es Salaam, UDSM)와 보건, 과학, 공학기술, 해양과학, 언어, 경영, 건축 등 다양한 분야에서 연구협력을 추진하였다. 이 때 사업비는 약 1,800 만 달러로 연간 360 만 달러를 연구 활동에 지원하였다. 이후 2009년부터 2014년까지 6년간은 탄자니아 과학기술위원회(Commission for Science and Technology, COSTECH)의 역량 강화를 지원하고, 28개 연구 프로젝트를 재정적으로 지원하였다. 이 때 사업비는 850만 달러가 투입되었다.

$\mathrm{SIDA} / \mathrm{SAREC}$ 의 추진사업은 매우 장기간에 걸쳐 이루어진다는 특징이 있다. 연구개발 성과 가 장기간에 걸쳐 획득되는 점을 감안할 때, 이는 비교적 일관되고 지속적인 지원을 추진할 수 있다는 점에서 바람직하다고 판단된다. 또, 특정 분야를 지원하기보다는 분야와 무관하게 연구 활동이라는 행위자체를 지원하고 있다. 


\section{6. 한국 국제개발협력단(KOICA)}

\section{가. 과학기술혁신 정책 마커(STI Marker)를 통한 지원성과 분석}

제I장

$\mathrm{KOICA}$ 는 2015년 과학기술혁신 분야 프로그램을 분류하기 위한 과학기술혁신 정책 마커 (STI Marker)를 개발하였다. 동 마커는 리우 마커나 젠더 마커와 같이 직접 목적 또는 간접 목적에 해당하는 사업에 점수를 부여하는 방식으로 구성되었다. 마커를 통해 과학기술혁신 프로그 램을 분류하려는 것은 과학기술혁신 개념이 범분야적 속성을 지니고 있다고 판단하였기 때문이다.

$\mathrm{KOICA}$ 의 STI 마커에서 직접 목적과 간접 목적을 분류하는 기준은 국가, 지역, 산업 단위 혁신시스템(Innovation System)의 관점을 적용하여 수립하였다. 지원하는 프로그램을 통해 수원국의 국가, 지역, 산업 단위 혁신시스템을 강화하는 것이 주 목적인 경우 과학기술혁신을 직접 목적으로 추구하는 프로그램으로 분류하는 것이다. 즉, 국가의 과학기술혁신 정책의 수립, 연구개발 인프라의 구축, 이공계 전문 인력의 양성, 기술사업화 등 연구개발 성과의 활용, 혁신 성과 관리를 위한 제도 구축 등과 같이 향후 지속적으로 기술혁신을 창출할 수 있는 물리적, 인적, 제도적 기반의 조성을 주목적으로 삼는 프로그램이 여기에 해당한다.

한편, 혁신시스템의 강화를 직접 목적으로 하지는 않더라도, 사업추진과정에서 특정 분야의 기술이 필연적으로 전수되는 경우가 있다. 예를 들어, 위성기술을 활용한 기상관측시스템 및 재해 조기경보시스템을 구축하는 사업의 경우, 이러한 장비를 통해 새로운 기술개발을 추구한다 고 보기는 어려우나 수원국에서 지원받은 장비를 활용하기 위해서는 분야 전문지식을 필연적으 로 획득해야만 한다. $\mathrm{KOICA}$ 의 STI 마커에서는 이와 같이 사업의 추진과정에서 기술력이 향상되는 사업을 간접 목적 사업으로 분류한다.

1991년부터 2014년까지 KOICA의 지원 실적을 KOICA STI 마커를 적용하여 분류한 결과 는 아래<그림 1 >과 같다. KOICA의 ODA 규모는 2009년 경제협력개발기구(Organization for Economic Cooperation and Development, OECD) 개발원조위원회(Development Assistance Committee, 이하 DAC) 가입을 기점으로 급격히 증가하였다. $\mathrm{DAC}$ 가입 후 2010년부터 2014년까지 5년간 KOICA의 지원액 중 STI 마커가 부여된 사업의 비중은 26\%-32\%에 달한다. DAC 가입 이전 2003년부터 2009년까지의 비중이 20 25\% 수준이었던 것과 비교할 때, 전체 사업예산의 증가와 함께 과학기술혁신 분야 프로그램의 비중도 확대된 것으로 분석된다. 
〈그림 1〉 KOICA 과학기술혁신 분야 지원 실적

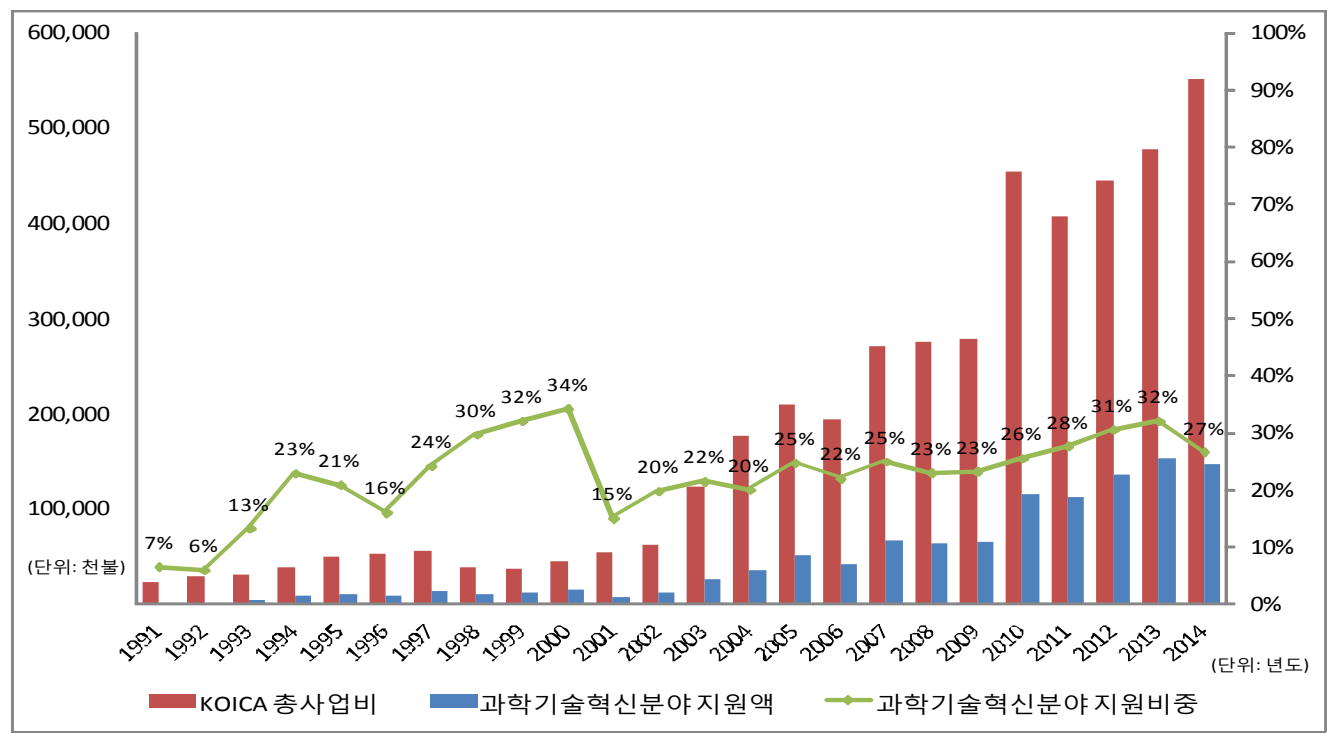

출처: 저자 작성

\section{나. 과학기술혁신 전략 및 SDGs 브랜드 프로그램4)}

$\mathrm{KOICA}$ 는 2015년, SDGs의 효과적 이행에 기여하고, 우리 정부의 '보다 나은 삶을 위한 과학기술혁신' 구상을 달성하기 위해 과학기술혁신 전략을 수립하였다. 동 전략은 세 가지 추진 목표로 1) 과학기술 분야의 핵심 연구 인력 양성, 2) 과학기술혁신 기반 산업발전 지원, 3) 혁신적 방식의 개발 문제 해결 활성화를 제시하고 있다. 각 전략 목표는 각각의 사업 발굴 유형을 갖는다. 그리고 이러한 전략 목표에 맞춰 발굴되는 사업들은 KOICA의 'SDGs 브랜드 프로그램'으로 분류되어 관리되고 있다.

첫 번째 전략목표 '과학기술 분야 핵심 연구인력 양성'에는 과학기술혁신 정책컨설팅 지원사 업, 과학기술인력 양성사업, 연구개발 인프라 구축 및 역량 강화 지원사업 등이 포함된다. 여기 서 과학기술 분야 핵심연구 인력의 범위에는 실험실에서 연구개발을 담당하는 이공계 전문 인력 이외에 과학기술정책이나 혁신정책을 수립하는 인력까지 포함하고 있다. 이는 개발도상국 의 과학기술혁신 역량구축을 위해서는 정책수립 역량이 중요하다는 인식을 바탕으로 한다고 볼 수 있다.

두 번째 전략목표 '과학기술혁신 기반 산업발전 지원’에는 과학기술 기반의 창업·취업 및

4) 이 부분의 내용은 KOICA의 업무자료를 바탕으로 작성하였다. 
기술이전 지원사업, 혁신클러스터 구축 및 강화 지원사업, 산학연 연계활동 지원사업, 산업발전 관련 제도 구축사업이 포함된다. 이와 같은 유형의 사업들은 과학기술 연구개발 활동이 실제 산업부문으로 연결되는 것을 지원하기 위한 목적을 가지고 있다. 이러한 유형에도 나타나는 것처럼, $\mathrm{KOICA}$ 의 과학기술혁신 사업은 특정 분야의 기술개발 활동을 지원하기보다는 전체적 인 시스템의 관점에서 과학기술혁신의 개별 주체들 간 상호작용을 연계시키고 관련 제도를 정비하는 것에 초점이 맞춰져 있다고 볼 수 있다.

세 번째 전략목표 '혁신적 방식의 개발 문제 해결 활성화'는 주로 민간의 기술혁신 역량을 개발 문제 해결에 끌어들이기 위한 노력을 의미한다. 동 목표에 부합하는 사업유형에는 KOICA 가 2015년 시작한 ‘창의적 가치창출(Creative Technology Solution, 이하 CTS) 프로그램'과 민간부문 과학기술혁신 역량을 활용한 개발도상국 지원사업이 있다. CTS 프로그램은 개발도 상국의 경제·사회적 문제를 해결하기 위한 기술개발을 지원하려는 목적으로 추진되며, 주로 스타트업을 대상으로 지원한다. CTS 프로그램은 미국 USAID의 'Global Development Lab' 을 벤치마킹하였으며, $\mathrm{KOICA}$ 의 기존 사업유형과 구별되는 새로운 형태의 지원방식을 만들었 다는 점에서 중요한 의미를 지닌다.

\section{7. 기관 간 프로그램 비교분석}

앞서 살펴 본 각 기관들의 주요 과학기술혁신 프로그램을 요약정리하고 비교한 내용은 아래 <표 2>에 나타나 있다. 양자원조 기관들 간의 특성을 요약하면, 먼저 USAID는 타 기관에 비해 월등히 많은 형태의 지원 프로그램을 찾아볼 수 있었다. 지원대상의 범위도 가장 넓다고 볼 수 있으며, 파트너십의 형태도 매우 다양하게 나타났다. 또, ‘Global Development Lab’과 같이 매우 실험적인 형식의 사업유형을 가장 먼저 시도하고 있는 것으로 나타나는 등, 가장 다양한 활동들을 추진하고 있는 것으로 분석된다.

$\mathrm{JICA}$ 와 SIDA는 주로 연구 활동을 지원하는 것으로 나타났다. 두 기관이 지원하는 연구 활동의 주제는 개발도상국의 경제개발과 직접 관련된 영역에 국한되지 않는다. 두 기관의 프로 그램은 이와 같은 공통점을 지닌다. 그러나 $\mathrm{JICA}$ 는 일본 내 과학기술 담당부처와 공동으로 과제를 선정하고 연구진을 파견하는 등 공동연구 추진에 중점을 두고 있지만, SIDA는 예산지 원 위주로 프로그램을 운영한다는 점에서 차이를 나타낸다.

$\mathrm{KOICA}$ 와 GIZ는 혁신시스템의 관점에서 종합적 접근을 한다는 점에서 유사성을 지닌다. 물론 두 기관이 추진하는 프로그램들이 다양한 요소들이 동시에 진행되는 종합적 성격을 띠는 
것은 아니다. 그러나 과학기술 연구개발 성과를 산업부문으로 연계시키는 것을 강조하고, 혁신 기반을 조성하기 위한 제도 구축 및 정책역량을 강화한다는 측면에서 공통점을 지닌다.

〈표 2〉 기관별 주요 과학기술혁신 프로그램의 비교

\begin{tabular}{|c|c|c|}
\hline 기관명 & 주요 프로그램 & 특징 \\
\hline UN & $\begin{array}{l}\cdot \text { 기술은행 } \\
\text { STI Supporting Mechanism } \\
\cdot \text { 기타 산하기관의 프로그램 } \\
\text { (UNICEF Innovation Lab) 등 }\end{array}$ & $\begin{array}{l}\text { 최빈국의 정보 접근성 향상을 위한 지식공유 } \\
\text { 플랫폼 } \\
\text { 연구 자료 및 정보교환을 위한 DB 구축 및 행 } \\
\text { 사 개최 }\end{array}$ \\
\hline USAID & $\begin{array}{l}\text { - Global Development Lab } \\
\text { - Partnership for Enhanced Engagement } \\
\text { in Research(PEER) } \\
\text { - Higher Education Partnership for } \\
\text { Innovation and Impact (HEPTI) 등 }\end{array}$ & $\begin{array}{l}\text { 프로그램의 지원대상이 매우 다양함 } \\
\text { 파트너십의 범위 또한 매우 다양함(개발도상국 } \\
\text { 전체, 특정 지역 국가군, 개별 국가 등) } \\
\text { 지원방식도 매우 다양함(연구재원 지원, 행사 } \\
\text { 개최, 프로젝트 지원 등) }\end{array}$ \\
\hline JICA & $\begin{array}{l}\text { Science and Technology Research } \\
\text { Partnership Program (SATREPS) }\end{array}$ & $\begin{array}{l}\text { 공동연구 과제 지원 중심 } \\
\text { 연구주제가 명확하며 연구진을 현지에 파견 } \\
\text { 환경, 자원, 식량 등 전 지구적 문제 해결에 초점 }\end{array}$ \\
\hline $\mathrm{GIZ}$ & $\begin{array}{l}\text { Promoting Innovation and Technology in } \\
\text { ASEAN Countries } \\
\text { Promotion of Innovation and Technology } \\
\text { for Small and Medium Sized Enterprises } \\
\text { in Near East }\end{array}$ & $\begin{array}{l}\text { 혁신시스템 관점에서 접근 } \\
\text { 연구개발 성과의 산업으로의 연계를 강조 }\end{array}$ \\
\hline SIDA & $\begin{array}{l}\text { 개발도상국 대학의 연구 과제 지원 프로그 } \\
\text { 램(탄자니아, 볼리비아 등) }\end{array}$ & $\begin{array}{l}\text { - 장기적 연구 활동을 지원 } \\
\text { - 연구분야의 범위가 매우 넓음 }\end{array}$ \\
\hline KOICA & $\begin{array}{l}\text { ·핵심 연구인력 양성 프로그램 } \\
\text { · STI 기반 산업발전 지원 프로그램 } \\
\text { ·혁신적 방식의 개발 문제 해결 활성화 프로 } \\
\text { 그램(CTS 등) }\end{array}$ & $\begin{array}{l}\text { 혁신시스템 관점에서 접근 } \\
\text { 프로젝트형 사업 비중 높음 }\end{array}$ \\
\hline
\end{tabular}

출처: 저자 작성 


\section{III. 결론}

국제사회의 SDGs 채택으로 인해 과학기술혁신은 국제 개발 협력에서 중요한 위치를 차지하 게 되었다. 개발도상국 과학기술혁신 역량의 강화는 개발도상국 스스로 경제적 부가가치를

창출할 수 있는 능력, 사회문제를 해결할 수 있는 능력으로 연결된다. 그리고 이러한 능력은 개발도상국의 지속가능한 발전에 기여할 것이다. 따라서 향후 15 년간 개발도상국의 과학기술혁 신역량을 강화하려는 국제사회의 다양한 노력들이 이어질 것이다. 국내에서도 정부 차원의 과학기술혁신 이니셔티브 발표를 계기로 여러 유관기관들이 추진전략을 수립하고, 사업모델을 준비하는 노력들이 관찰된다.

그러나 과학기술혁신의 개념은 다양한 해석이 가능하다는 점을 감안할 때, 자칫 어떤 프로그 램이든 과학기술혁신 프로그램으로 포장하는 상황이 발생할 우려가 있다. 매우 이질적인 여러 사업들이 과학기술혁신 프로그램이라는 하나의 범주로 묶이게 되면 프로그램의 성격 자체가 모호해 질 수 있고, 프로그램 수행결과로부터 교훈을 얻어 개선된 프로그램을 만드는 것이 어려워질 수 있다. 따라서 과학기술혁신은, 국가 단위 혹은 기관 단위의 전략수립이 반드시 필요한 주제라고 할 수 있다. 비록 많은 프로그램 사례 중 일부에 불과하나, 앞서 제시한 여러 원조기관들의 사례들은 이러한 전략 수립의 과정에서 유용하게 활용될 수 있을 것이다. 


\section{〈참고문헌〉}

국무조정실. 2016. “개발 협력 4대 구상 이행 마스터플랜." 제 24 차 국제개발협력위원회 회의자료(2016.02.29.). 세종: 국무조정실.

이근. 2014. 『경제추격론의 재창조: 기업·산업·국가 차원의 이론과 실증』. 서울: 도서출 판 오래.

이우성. 2014. “우리나라의 과학기술 ODA 현황과 발전방향.” 『과학기술정책』. 제24권 제 1 호. 세종: 과학기술정책연구원.

이우성, 이명진, 장용석, 정도채, 성경모, 박선희, 김성아, 김보현, 정유성, 윤성빈, 김아람.

2015. “UN의 Post-2015 개발의제와 과학기술혁신 국제협력 방안." 『정책연구』

2015-18. 세종: 과학기술정책연구원: 1-434.

한국국제협력단. 2015. 『지속가능개발목표(SDGs) 수립현황과 대응방안』. 성남. 한국국 제협력단.

. 2016. “과학기술혁신 중장기 전략” (내부 문서). 성남: 한국국제협력단

GTZ. 2010. "Strengthening Innovation Systems in the Context of Development

Cooperation" (workshop document), held 5-8 October 2009 in Dortmund, Germany.

UN. 2011. "Programme of Action for the Least Developed Countries for the Decade 2011-2020.”New York: UN.

. 2013. "Technology bank and science, technology and innovation supporting mechanism dedicated to the least developed countries." (A/68/217). New York: UN.

. 2015a. "Resolution adopted by the General Assembly on 25 September 2015.”(A/RES/70/1). New York: UN.

. 2015b. "Feasibility Study for a United Nations Technology Bank for the Least Developed Countries."(A/70/408). New York: UN. 